\title{
Agenesis of inferior vena cava associated with deep venous thrombosis
}

\author{
Agenesia de veia cava inferior associada à trombose venosa profunda \\ Clovis Luis Konopka ${ }^{1}$, Marcelo Salame², Geórgia Andrade Padulla², Raquel Rodrigues Muradás ${ }^{3}$, Julio César Batistella ${ }^{4}$
}

\begin{abstract}
The agenesis of the inferior vena cava is a rare congenital anomaly, which was recently identified as an important risk factor for the development and recurrence of deep venous thrombosis especially in young people. The goal of this work was to report the case of a patient who presented deep venous thrombosis approximately two months after varicose vein surgery. The CT angiotomography demonstrated a complex venous anomaly with absence of the inferior vena cava.
\end{abstract}

Keywords: cardiovascular abnormalities; vena cava, inferior; venous thrombosis.

\section{Resumo}

A agenesia da veia cava inferior é uma anomalia congênita rara, que foi recentemente identificada como um importante fator de risco para o desenvolvimento e a recorrência de trombose venosa profunda de membros inferiores em jovens. O objetivo deste trabalho foi relatar o caso de uma paciente que apresentou trombose venosa profunda dois meses após a realização de cirurgia de varizes. A angiotomografia computadorizada demonstrou a presença de anomalia venosa complexa com ausência da veia cava inferior.

Palavras-chave: anormalidades cardiovasculares; veia cava inferior; trombose venosa.

\section{Introduction}

Deep venous thrombosis (DVT) is relevant because of its high frequency and morbidity/mortality rates. Its prevalence in the western population is estimated to be $1: 1,000$ individuals per year ${ }^{1-3}$. The prevalence varies according to age, being ten times lower in 20 to 40 year-old individuals than in older age groups $s^{2,3}$.

In young patients, its etiology is frequently associated with risk factors such as congenital and acquired thrombophilia, autoimmune diseases, pregnancy and puerperium, use of oral contraceptives, neoplasms, surgical procedures, prolonged immobilization and trauma. The most common types of thrombophilia are: protein $\mathrm{C}$ and $\mathrm{S}$ deficiencies, resistance to $\mathrm{C}$-reactive protein, prothrombin G20210A gene mutation, hyperhomocysteinemia, and antiphospholipid syndrome. Such thrombophilias may be found in 5 to $10 \%$ of the DVT cases ${ }^{1}$, and one or more risk factors may be identified in over $80 \%$ of these patients ${ }^{1,4,5}$.

The increasing use of CT angiography and magnetic resonance imaging (MRI) has allowed physicians to identify more frequently the presence of inferior vena cava (IVC) malformations associated with DVT of the lower limbs ${ }^{1,4,5}$. Some studies report the presence of a type of IVC anomaly in approximately $5 \%$ of young patients, which suggests that this condition is a new risk factor for DVT ${ }^{1,6}$.

The prevalence of IVC anomalies in the general population is estimated in 0.07 to $8.7 \%^{1,7}$. Such conditions may be associated with vague and unspecific symptoms or, in many cases, may be completely asymptomatic.

In most studies, the most common IVC malformations are hypoplasia of the prerenal and renal segments, followed by hypoplasia of the postrenal segment and IVC

\footnotetext{
Study carried out at the University Hospital Santa Maria of UFSM, Santa Maria (RS), Brazil.

1 Assistant Professor of Vascular Surgery at the Service of Endovascular Surgery of Hospital Universitário de Santa Maria (UFSM), Santa Maria (RS), Brazil.

${ }^{2}$ Medical student at UFSM; Instructor at the Service of Vascular Surgery of University Hospital Santa Maria of UFSM, Santa Maria (RS), Brazil.

${ }^{3}$ Medical student at UFSM, Santa Maria (RS), Brazil.

${ }^{4}$ Radiologist at DIX - Diagnóstico por Imagem, Santa Maria (RS), Brazil.

No conflict of interest was declared concerning the publication of this article.

Received on: Mar 19, 2010. Accepted on: Jun 1, 2010

J Vasc Bras. 2010;9(3):196-199.
} 
duplicity ${ }^{5}$. In such cases, the first episode of DVT generally occurs before the age of 30 , with similar incidence in men and women ${ }^{5}$.

This paper describes a case of complex congenital malformation with absent IVC in association with DVT.

\section{Case report}

A 43-year-old Caucasian saleswoman presented with superficial, dilated and tortuous symptomatic veins (clinical classification: CEAP II) affecting the lower limbs. She had a history of two pregnancies with cesarean delivery at term and family history of varicose veins of the lower limbs. The surgical treatment of varicose veins was indicated after Color Doppler ultrasonography. The patient underwent bilateral great saphenous vein stripping under epidural anesthesia and discharged 24 hours later.

Two months after the procedure, the patient presented sudden pain and edema on the right inferior limb. Color Doppler ultrasonography confirmed the suspected acute iliofemoral DVT on the right side and showed absence of IVC in its usual topography and reduced diameter of the right common iliac vein.

Thoracic and abdominal CT angiography confirmed the absence of the IVC. (Figure 1) and stenosis on the thoracoabdominal transition of a large vein located on the left side of the aorta (Figure 2). In the lower abdomen, reduction of the right common iliac vein diameter was observed in comparison to its left counterpart. The common iliac veins and both renal veins drained into the anomalous vein on the left side of the aorta (Figure 3), which ascended to the thorax, with confluence of left upper limb and left cervical region vessels. The veins of the right upper limb, cranium and right cervical region formed the superior vena cava.

The patient was treated with anticoagulant therapy with unfractionated heparin by endovenous infusion (18 UI/kg/h) adjusted by activated partial thromboplastin time (aPTT) (2.5 times the initial value) for 7 days, followed by oral anticoagulation with antivitamin $\mathrm{K}$ (Warfarin sodium ${ }^{\circ}$ ). The International Normalized Ratio (INR) was maintained between 2 and 3 during 6 months. At the end of treatment, the patient still had mild edema of the right ankle and almost complete venous recanalization, confirmed by color Doppler ultrasonography. An investigation for thrombophilia was performed by dosing antithrombin, homocysteine and $\mathrm{C}$ and $\mathrm{S}$ proteins, Factor $\mathrm{V}$ of Leiden, prothrombin mutation, anticardiolipin anti- bodies (IgM and $\operatorname{IgG}$ ), and lupus anticoagulant antibody. The results were negative.

\section{Discussion}

Embryologic abnormalities of the IVC and its tributaries are rare ${ }^{1,2,4,8}$. To date, 15 different types have been reported, and the most common ones are left IVC, double

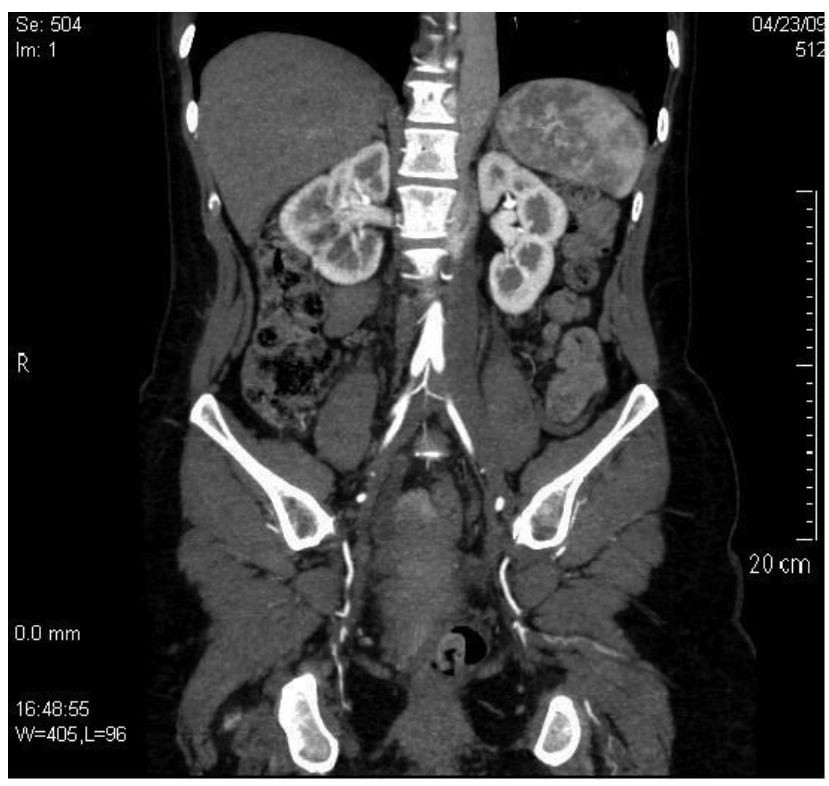

Figure 1 - Coronal reconstruction of contrast CT angiography showing absence of the inferior vena cava in its habitual topography, right common iliac vein with reduced diameter, venous drainage by a vessel on the left side of the aorta

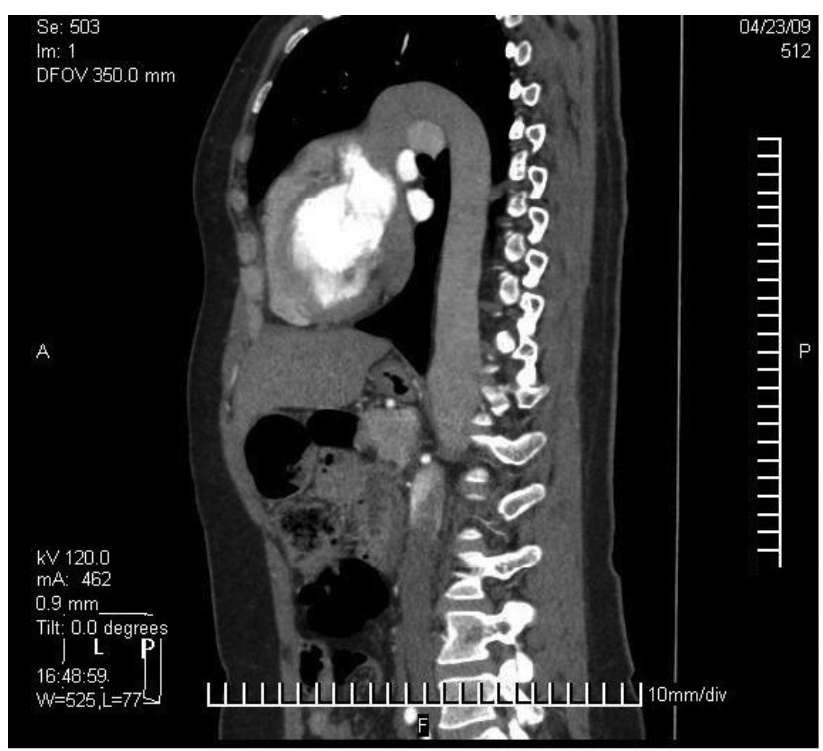

Figure 2 - Sagittal reconstruction of CT angiography showing nonhabitual venous drainage and narrowing of the vessel on the transition of the thorax to the abdomen 


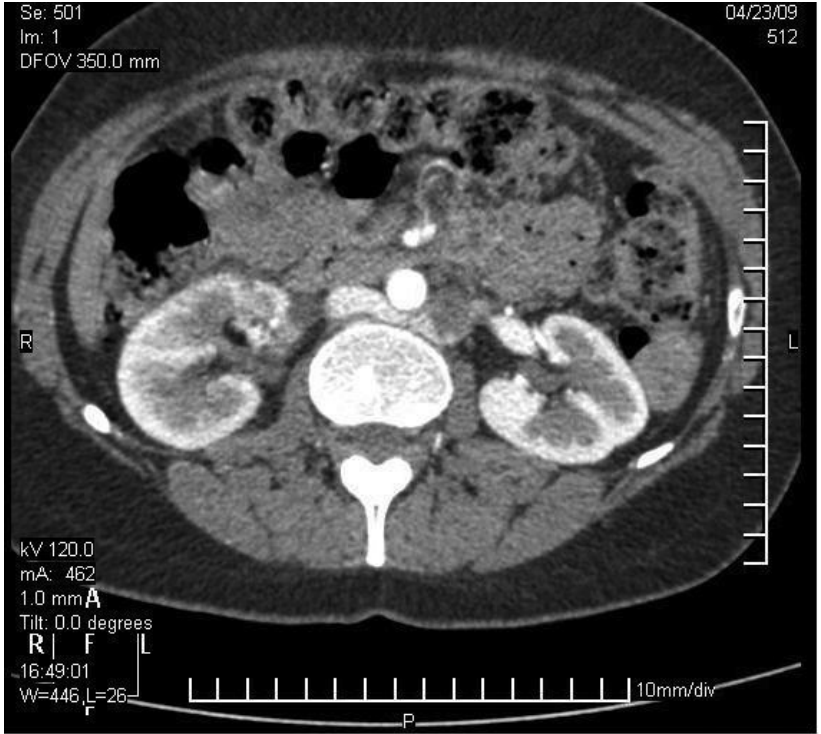

Figure 3 - Axial cut of contrasted CT angiography showing that the right renal vein drains into the vessel that corresponds to the inferior vena cava, to be found at the left side of the aorta

IVC, azygos continuation, retroaortic left renal vein and complete agenesis of the IVC. These anatomical variations occur between the sixth and eighth weeks of embryonic development ${ }^{1,4,7,9}$.

The embryogenesis of the IVC is a complex event that involves formation, regression and fusion of three pairs of embryonic veins $s^{1,3,7,8,10}$. The infrahepatic segment of the IVC may be divided in three parts: suprarenal, renal and infrarenal; the right subcardinal vein becomes the suprarenal segment; the supracardinal anastomoses with the subcardinal vein originates the renal segment, and the infrarenal segment emerges from the right supracardinal vein ${ }^{1,5,8,9}$. Agenesis of the IVC suggests the simultaneous occurrence of a defect in all three embryonic segments ${ }^{1,4,6,8}$.

The etiology of the IVC agenesis is controversial in literature. Some authors suggest that thrombosis on the IVC during the perinatal period is the origin of its disappearance, hence no embryologic abnormalities are seen $^{1,3,9}$. IVC agenesis or hypoplasia may be accompanied by other congenital abnormalities such as splenic anomalies, disorders of intestinal rotation, pulmonary dysgenesis, renal agenesis, dextrocardia and other congenital heart diseases ${ }^{1,3,4,9,11}$. These anomalies are identified in over $1 \%$ of the patients, but the incidence may reach $2 \%$ of the patients with congenital heart disease $\mathrm{e}^{1,6,12}$.

In total absence of IVC, the venous drainage through thoracolumbar, pelvic and abdominal veins may result in symptoms on thorax, hypogastrium, lumbar and genital regions before the occurrence of lower limbs' $\mathrm{DVT}^{6}$ Although these symptoms are rare and unspecific, their early detection in young patients may indicate the presence of an IVC malformation ${ }^{5}$.

Patients with IVC anomalies are prone to DVT due to the venous stasis of the lower limbs ${ }^{1,4}$. In the case described, the patient had iliofemoral DVT of the right lower limb, which could be related to the markedly decreased right common iliac vein caliber observed in the imaging exams (Figure 1).

The improvement in imaging exams and their increasing use have led to frequent detections of anatomical variations and IVC anomalies ${ }^{4}$. The best imaging methods for the diagnosis of IVC anomalies are CT angiography and MRI and the diagnosis is considered to be difficult when ultrasonography is used alone $e^{3,4,6,13,14}$.

The presence of spontaneous, recurrent and sometimes bilateral proximal lower limb DVT in young patients must call the assistant physician's attention to the possibility of an IVC anomaly. MRI and contrast CT angiography are especially useful in such cases ${ }^{5,11,15}$. However, DVT as a paraneoplasic manifestation or as a result of a hypercoagulable state must also be excluded ${ }^{11}$.

The most appropriate treatment in such cases is anticoagulation for at least six months. The possibility of recurrence is high when the patient has the anticoagulation treatment discontinued before this period ${ }^{5}$.

\section{Conclusion}

Patients with congenital IVC anomalies associated with DVT are significantly younger in comparison to patients with isolated DVT of the lower limbs. The DVT is related to venous stasis of the lower limbs, which may be bilateral in over $50 \%$ of the cases. Besides, there are elevated indexes of thrombosis recurrence due to inadequate venous return and consequent venous stasis.

Surgical intervention is rarely indicated; only anticoagulation is recommended as the ideal treatment. There is no consensus in literature about the duration of the anticoagulant treatment. Some authors ${ }^{1,3,7}$ recommend life-long anticoagulation even when thrombophilia investigation is negative in order to reduce the recurrence risk.

Finally, it is worth emphasizing that young patients with DVT that is not associated with classical risk factors should undergo a complete investigation, including IVC imaging methods, with the objective of excluding possible congenital venous anomalies. 


\section{References}

1. Cho BC, Choi HJ, Kang SM, et al. Congenital absence of inferior vena cava as a rare cause of pulmonary thromboembolism. Yonsei Med J. 2004;45:947-51.

2. Milani $C$, Constantinou $M$, Berz $D$, et al. Left sided inferior vena cava duplication and venous thromboembolism: case report and review of literature. J Hematol Oncol. 2008;1:24-7.

3. Iqbal J, Nagaraju E. Congenital absence of inferior vena cava and thrombosis: a case report. J Med Case Reports. 2008;2:46-9.

4. Suh HJ, Kim WT, Kim MY, et al. Combined anomaly of the right hepatic lobe agenesis and absence of the inferior vena cava: a case report. Koren J Radiol. 2008;9:561-4.

5. García-Fuster MJ, Forner MJ, Flor-Lorente B, et al. Inferior vena cava malformation and deep venous thrombosis. Rev Esp Cardiol. 2006;59:171-5.

6. Gayer G, Luboshitz J, Hertz M, et al. Congenital anomalies of the inferior vena cava revealed on $C T$ in patients with deep vein thrombosis. AJR Am J Roentgenol. 2003;180:729-32.

7. Obernosterer A, Aschauer M, Schnedl W, Lipp RW. Anomalies of the inferior vena cava in patients with iliac venous thrombosis. Ann Intern Med. 2002;136:37-41.

8. Yigit $\mathrm{H}$, Yagmurlu, Yigit $\mathrm{N}$, et al. Low back pain as the initial symptom of inferior vena cava agenesis. AJNR Am J Neuroradiol. 2006;27:593-96

9. Bass JE, Redwine MD, Kramer LA, et al. Absence of the infrarenal inferior vena cava with preservation of the suprarenal segment as revealed by CT and MR Venography. AJR Am J Roentgenol. 1999;172:1610-2.

10. Mano A, Tatsumi T, Sakai H, et al. A case of deep venous thrombosis with a double inferior vena cava effectively treated by suprarenal filter implantation. Jpn Heart J. 2004;45:1063-9.
11. Atmatzidis K, Papaziogas B, Pavlidis T, et al. Surgical images: soft tissue. Recurrent deep vein thrombosis caused by hipoplasia of the inferior vena cava. Can J Surg. 2006;49:285.

12. Felício ML, Martins AS, Andrade RR, et al. Ausência parcial de veia cava inferior associada à malformação intestinal. Rev Bras de Cirurgia Cardiovascular. 2007;22:362-4.

13. Gay SB, Armistead JP, Weber ME, et al. Left infrarenal region: anatomic variants pathologic conditions, and diagnostic pitfalls. Radiographics. 1991;11:549-70.

14. Onzi RR, Costa LF, Angnes RF. Malformação de veia cava inferior e trombose venosa profunda: fator de risco de trombose venosa em jovens. J Vasc Bras. 2007;6:186-9.

15. Viana SL, Mendonça JLF, Freitas FMO, et al. Hipoplasia da veia cava inferior: relato de caso e revisão da literatura. Rev Imagem. 2006;28:203-7.

Correspondence:
Clovis Luis Konopka
Rua Duque de Caxias, 1.668/803 - Centro
CEP: $97015-190$ - Santa Maria (RS), Brasil
E-mail: konopka@terra.com.br
Authors' contributions
Study conception and design: CLK, MS and GAP
Data analysis and interpretation: N/I
Data collection: N/I
Writing of the paper: CLK, MS, RRM and JCB
Critical analysis: CLK and MS
Final text approval*: CLK
Statistical analysis: N/I
Overall responsibility: CLK
Financing information: N/I
*All authors have read and approved the final version of the paper submitted
to the J Vasc Bras.

